\title{
Article \\ Media and Responsibility for Their Effects: Instrumental vs. Environmental Views
}

\author{
Andrey Miroshnichenko (D)
}

Communication \& Culture, York University, Toronto, ON M3J 1P3, Canada; andrey.mir70@gmail.com

Citation: Miroshnichenko, Andrey. 2021. Media and Responsibility for

Their Effects: Instrumental vs.

Environmental Views. Laws 10: 48. https://doi.org/10.3390/

laws10020048

Received: 28 April 2021

Accepted: 9 June 2021

Published: 11 June 2021

Publisher's Note: MDPI stays neutral with regard to jurisdictional claims in published maps and institutional affiliations.

Copyright: (C) 2021 by the author. Licensee MDPI, Basel, Switzerland. This article is an open access article distributed under the terms and conditions of the Creative Commons Attribution (CC BY) license (https:/ / creativecommons.org/licenses/by/ $4.0 /)$.

\begin{abstract}
From the perspective of media ecology, this paper explores the question of responsibility for the effects that media have on society. To explain these media effects, two approaches are singled out. (1) The instrumental approach assumes that a medium works as a tool used by a user for a purpose. (2) The environmental approach focuses on the capacity of a medium to become an environmental force that reshapes both the habitat and the inhabitants. The instrumental approach to media, when taken too broadly and without an understanding of its limits, leads to conspiracy theories and inadequate social and political assessments. The more advanced and sophisticated environmental approach allows for an adequate understanding of media evolution and its effects but does not comply with the traditional legal notions of guilt and responsibility for actions, as there is no jurisdictional human or institutional agency when environmental forces are in play. After charting the distinction between the instrumental and environmental views of media, the paper focused on how the instrumental effects of media turn into environmental effects. The purpose of the paper is to develop and offer a media ecological apparatus for possible further juridical discussions regarding the regulation of the networking society.
\end{abstract}

Keywords: media effects; internet regulation; media ecology; social media; Marshal McLuhan

\section{Introduction. The Trap of the Instrumental Approach to Media Effects}

It is admitted in the news media and among the political elites and experts that the internet has become a tool of the alt-right movement and other forces aimed at destroying Western democracy. The media consistently provide evidence of how the alt-right uses the internet, with headlines such as "How the alt-right uses internet trolling to confuse you into dismissing its ideology"1, "The alt-right's dark army of racist trolls just had a great day"2, "The alt-right created a parallel internet. It's an unholy mess"3, and the like.

Among "the usual suspects" (Benkler et al. 2018) who use the internet to distort democracy, Russian operatives have to be mentioned. As Hillary Clinton stated some time ago, "Russian trolls and bots and agents are still fomenting discord and conflict within our country. That is classic propaganda, and the Russians are really good at it."4

Interestingly, Russian President Vladimir Putin shares a similar view regarding the internet but with one exception. He is confident that it is American operatives who are using the internet to undermine sovereignty and democracy in Russia. He said:

1 Romano, Aja. (11 January 2017). How the alt-right uses internet trolling to confuse you into dismissing its ideology. Vox. https://www.vox.com/20 16/11/23/13659634/alt-right-trolling (accessed on 16 April 2021).

2 Lapowsky, Issie. (25 August 2016). The Alt-Right's Dark Army of Racist Trolls Just Had a Great Day. Wired. https://www.wired.com/2016/08/altrights-dark-army-racist-trolls-just-great-day/ (accessed on 16 April 2021).

3 Roose, Kevin. (11 December 2017). The Alt-Right Created a Parallel Internet. It's an Unholy Mess. The New York Times. https://www.nytimes com/2017/12/11/technology/alt-right-internet.html (accessed on 16 April 2021).

4 Hoffman, Ashley. (2 November 2017). Hillary Clinton: Russia's 2016 Election Meddling Is a 'Form of War'. Time. https://time.com/5007112/ hillary-clinton-trump-russia-daily-show/ (accessed on 16 April 2021). 
Everything goes through servers in the [United] States, everything is controlled from there ... As you know, all this emerged once, at the beginning of the internet, as a special project of the CIA. And thus, it has been developing since then. ${ }^{5}$

On another occasion in 2019, answering a question about the risks for Russia to be disconnected from the Global Web, he said:

I can't speak for our partners, what they have in mind ... I think this will cause them enormous damage ... Because they're sitting there, it's their invention. And they listen, see and read everything you say, and accumulate this information ... ${ }^{6}$

The review of the attitude of public and political elites shows that all involved, first, see the internet as a damaging tool and, second, see the internet as a damaging tool in the hands of their opponents. It is obvious that such an attitude relates not so much to the essence of media effects but rather to the political stances of the evaluators of media effects. At the same time, such an attitude shapes the pressing and growing demand for regulation of the internet and social media. A situation emerges when the regulation of the object is exclusively based on the stances of the subject but has little or nothing to do with the real character of the object. While such deviation is not uncommon in politics, it may cause problems in legal regulations.

The controversy and inconsistency of connecting media effects with the user's intent are particularly visible through the historical analysis of praising or blaming the same media for the same media effects but in the hands of different users.

For example, since recently Twitter has been perceived as a malicious tool because it can easily be used by a malicious actor, as it was widely acknowledged that Twitter not only provided a platform to the alt-right but also helped Donald Trump bypass the mainstream media and highjack the agenda in 2016 (Owen 2019; Enli 2017). On the other hand, Twitter was considered a progressive tool in the US 2008 election, when a presidential candidate, Barack Obama, was widely praised for the use of Twitter as a way to bypass the mass media and reach out to voters directly and personally (Owen 2019). Not to mention the progressive role of Twitter in the protest movements of the early 2010s, such as the Arab Spring and others, when Twitter was seen as a beacon of democracy helping to organize the grassroot protests against political establishments.

Similar historical confusion can be observed regarding the use of covert social media accounts for ideological influence. The use of fake accounts by the Russians to undermine the electoral process in the USA was exposed and condemned during investigations into foreign meddling in the 2016 US presidential election. It was found that fake accounts affiliated with the Russians bought USD 100,000 in political ads on Facebook during the campaign. ${ }^{7}$

However, historically, the first mentions of the fake accounts' and troll farms' use for meddling abroad appeared in the media in 2011 and were tied to the American military. The Guardian revealed that "the US military is developing software that will let it secretly manipulate social media sites by using fake online personas to influence internet conversations and spread pro-American propaganda." An "online persona management service" would allow one US operator "to control up to 10 separate identities based all over the world." 8

One of the most talked of media effects, the use of social media personal data for political targeting, has not avoided this fate of being blamed or praised with regard to who

5 Agamalova, Anastasia, and Golitsyna, Anastasia. (24 April 2014). Putin is sure that the internet appeared as the special project of CIA. Vedomosty.Агамалова, Анастасия, иГолицына, Анастасия. (2014, 24 апреля). Путин уверен, что интернет возник как спецпроект ЦРУ. Ведомости. https: / www.vedomosti.ru/technology/articles/2014/04/24/putin (accessed on 16 April 2021).

6 ВВС. (21 February 2019). What Putin said about the internet and it prospect in Russia.—ВВС. (2019, 21 февраля). Что Путин говорилоб интернете и его судьбе в России. https:/ /www.bbc.com/russian/news-47317481 (accessed on 16 April 2021)

7 Shane, Scott, and Goel, Vindu. (6 September 2017). Fake Russian Facebook accounts bought $\$ 100.000$ in political ads. The New York Times. https:/ / www.nytimes.com/2017/09/06/technology/facebook-russian-political-ads.html (accessed on 16 April 2021).

8 Fielding, Nick, and Cobain, Ian. (17 March 2011). "Revealed: US spy operation that manipulates social media". The Guardian. https://www. theguardian.com/technology/2011/mar/17/us-spy-operation-social-networks (accessed on 16 April 2021). 
uses it. Thus, Obama's re-election team in 2012 was praised for "building a vast digital data operation that, for the first time, combines a unified database on millions of Americans with the power of Facebook to target individual voters to a degree never achieved before", as reported by the Guardian in 2012. ${ }^{9}$ The media cheered the efforts with naïve admiration:

[ ... ] a crack team of some of America's top data wonks $<\ldots>$ draws much of its style and inspiration from the corporate sector, with its driving ambition to create a vote-garnering machine that is smooth, unobtrusive and ruthlessly efficient. < . . > If 2008 was all about social media, 2012 is destined to become the 'data election'. ${ }^{10}$

The people developing the technology were called "the digital wizards behind Obama's tech-heavy re-election strategy". 11

But on a different occasion, the psychographic profiling with personal data collected on social media and used for the precisely customized delivery of politically charged content caused a scandal and investigations after Trump's shocking victory in 2016. "Digital wizards" from Cambridge Analytica were blamed and accused rather than praised.

So, is Twitter good or bad? Should faking one's identity be prohibited? Are data profiling and social media message customization good or bad? Do social media serve democracy or evil? Or does it just depend on who is the user?

The answer that comes first is that the internet and social media amplify the activity of the actor using it. Such an answer usually satisfies both experts and the lay public.

When media are seen as mere tools of some actor, they lose their own media property and present or amplify the property of a user. This is comparable to an acknowledgment that "guns don't kill people, people do", an argument of "media neutrality" or medianothingness, as if media do not have their own characteristics. Within this approach, any media analysis gets reduced to the analysis of the user's intent, meaning there is no media analysis at all.

Moreover, when media are seen as tools, they are always perceived as tools in the wrong hands. For some mystical reasons, bad actors or, worse, conspirators always take over any medium. If a medium is seen as an instrument, the detection of a conspiracy behind its use will not take long. This approach has never reported a "right" instrumental use of a medium. Within the consensus regarding the "amplifying" role of media, it is most often admitted that media a posteriori "amplify" evil, whereas the task to "amplify" good is seen as ideal-something that is desired but not yet achieved. The service of media to good is always what must happen, whilst the service of media to evil is always what happens in reality.

This creates a potentially dangerous demand to regulate media in such a way that they would serve only those who are seen as "right" or "good" actors, while the access of others would be restricted. Thus, the burden of regulation shifts from defining the norms of media supply to defining which users are good or bad and, therefore, should be banned or admitted for media use. Considering the fact that the regulation is always politically induced and often politically executed, such a regulatory approach might create a bigger danger for democracy than the harm it is meant to regulate.

To separate media effects from the users' intents and, therefore, to separate judging media from judging users, this paper developed a distinction between the instrumental and environmental approaches to media effects.

1. The instrumental approach assumes that a medium works as a tool used by a user for a purpose.

9 Pilkington, Ed, and Michel, Amanda. (17 February 2012). "Obama, Facebook and the power of friendship: The 2012 data election”. The Guardian. https:/ / www.theguardian.com/world/2012/feb/17/obama-digital-data-machine-facebook-election (accessed on 16 April 2021).

10 Pilkington, Ed. (17 February 2012). "The digital wizards behind Obama's tech-heavy re-election strategy". The Guardian, https://www.theguardian. com/world/2012/feb /17 / obama-campaign-digital-team (accessed on 16 April 2021).

11 Ibid. 
2. The environmental approach focuses on the capacity of a medium to become an environmental force that reshapes both the habitat and inhabitants. ${ }^{12}$

An analysis similar to the one described above shows the prevalent inclination of experts and the public to recognize as media effects only those that are, in fact, the instrumental effects of media. This view is as easily induced as it is easily confused by assigning effects to the intents of the user. Therefore, this approach renders a researcher blind to the work and effects of media themselves. As a result, the risk of a misguided regulation appears when supposedly media-targeted regulation turns out to be user-targeted regulation with a completely different level of political risks and potential harm to democracy. The instrumental approach to media regulation is potentially wrong, even technically, because it effectively does not regulate what it is supposed to-it regulates users instead of media while declared as media regulation. The very purity of the spirit and letter of law is misguided when the instrumental view of media effects takes over.

Media ecology allows seeing the environmental effect of media behind its instrumental use. By distinguishing the instrumental and environmental views of media effects, this paper aimed to develop a media ecological apparatus that could potentially be helpful for juridical discussions on media regulation.

The second section of the paper investigates the popularity of the instrumental view of media effects as related to the powerful Lasswellian tradition in communication studies with its famous formula "Who says what, in which channel, to whom, with what effect?"

The third section offers the apparatus and ideas of media ecology for charting the distinction between the instrumental and environmental views of media effects.

The fourth section explores the emergence of the environmental effect of a medium from its instrumental use through the impact of a medium's use on the sensorium.

The fifth section explores the development of the environmental effect of a medium from its instrumental use through the impact of a medium's use on culture.

The sixth section probes into the difference between the instrumental and environmental views of media effects for possible application in defining the responsibility of the user, producer, and supplier of a medium. This is the border zone, where media ecology hands its findings and revelations to jurisprudence for possible further investigation and application.

\section{The Lasswellian Instrumental Tradition in Communication Studies}

The instrumental approach has dominated communication studies. The practical, "administrative" approach to communications originated from the famous Lasswell model "Who says what, in which channel, to whom, with what effect?" (Lasswell 1948, p. 37). The instrumental view of media made this model universal. It has been routinely used and continues to be used for the explanation of any communication and broader technological effect.

The Lasswell model was graphically first represented by McQuail and Windahl in 1981 as a cybernetic-looking sequence of blocks of meaning (according to Sapienza et al. 2015; reprinted here is Lasswell's graphic model from McQuail and Windahl [1982] 1993, p. 13; Figure 1).

The Lasswell model was applied and developed multiple times in adjacent fields. Thus, C.E. Shannon and W. Weaver developed this formula for their information theory, which reflects a cybernetic view of communication and centers on the "signal/message" passage through "nodes" (McQuail and Windahl [1982] 1993, p. 17; Figure 2).

The communication theory, the information theory, and cybernetics emerged and started developing at approximately the same time. Not surprisingly, their epistemological approaches can be considered identical. This, in part, can explain the significant role of the information-theory syntax of "subject-action-object" and the cybernetic way of "meaning-

12 The idea of the distinction between the instrumental and environmental approaches to media effects was first introduced in: Miroshnichenko (2020). "The hardware and software of Trumpism: A figure/ground analysis." Explorations in Media Ecology, Volume 19, Number 1, 1 March 2020, pp. 55-84(30). Intellect. DOI: https://doi.org/10.1386/eme_00024_1. 
packaging" (even visually—in the blocks) in the communication theory, with its view of communication as a stepwise and linear act.

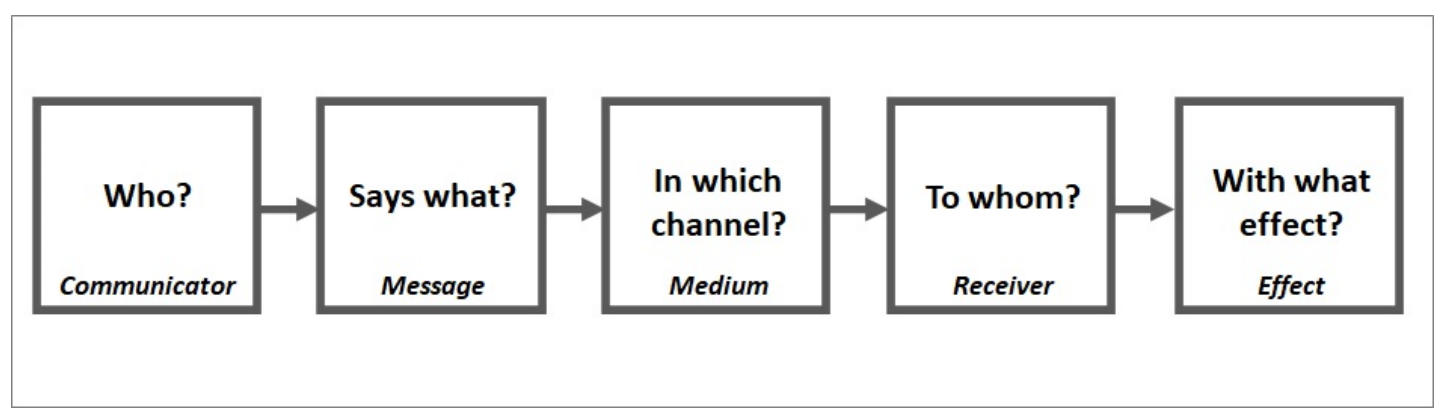

Figure 1. The Lasswell Formula with corresponding elements of the communication process (according to McQuail and Windahl [1982] 1993, p. 13).

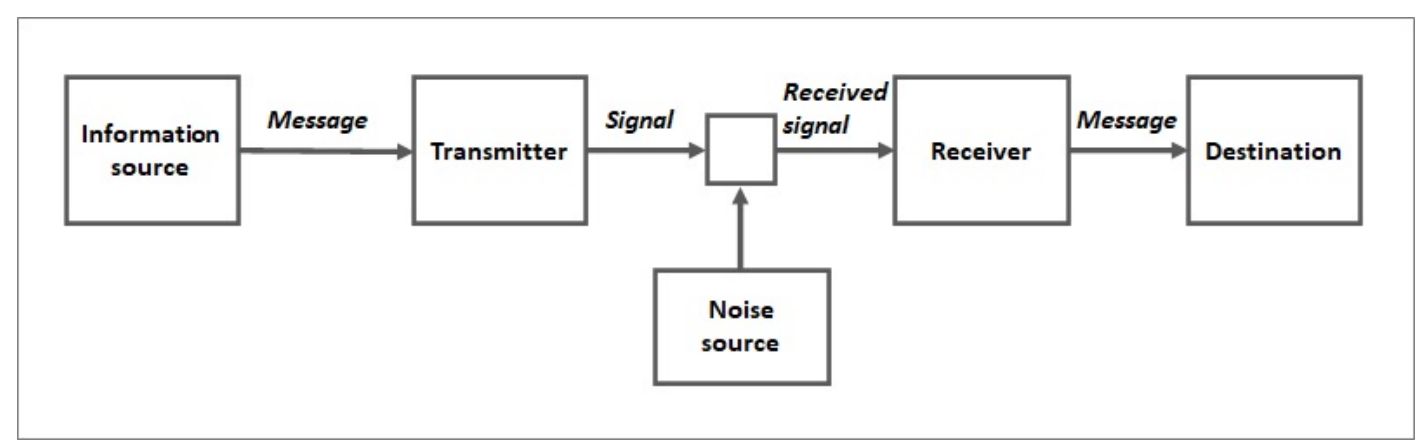

Figure 2. Shannon and Weaver's development of a linear communication model (according to McQuail and Windahl [1982] 1993, p. 17).

Shannon and Weaver focused on the better encoding and reliable transmission of the signal in order to avoid information loss. Their interest was in the side of the sender and the technical reliability of communication. Stuart Hall (the Birmingham School of cultural and communication studies), on the contrary, looked at the communication act from the receiver's side. He developed a similar formula for his reception theory. In discussing encoding and decoding in mass communication (TV), Hall explored how much room the receiver has for the "negotiation" of transmitted meaning and what cultural conditions predefine this room for negotiation. Even though Hall added a profound semiotic analysis to the interpretation of the (mass) communication act, the formula itself remained quite simple and linear (Hall [1973] 2012, p. 138; Figure 3).

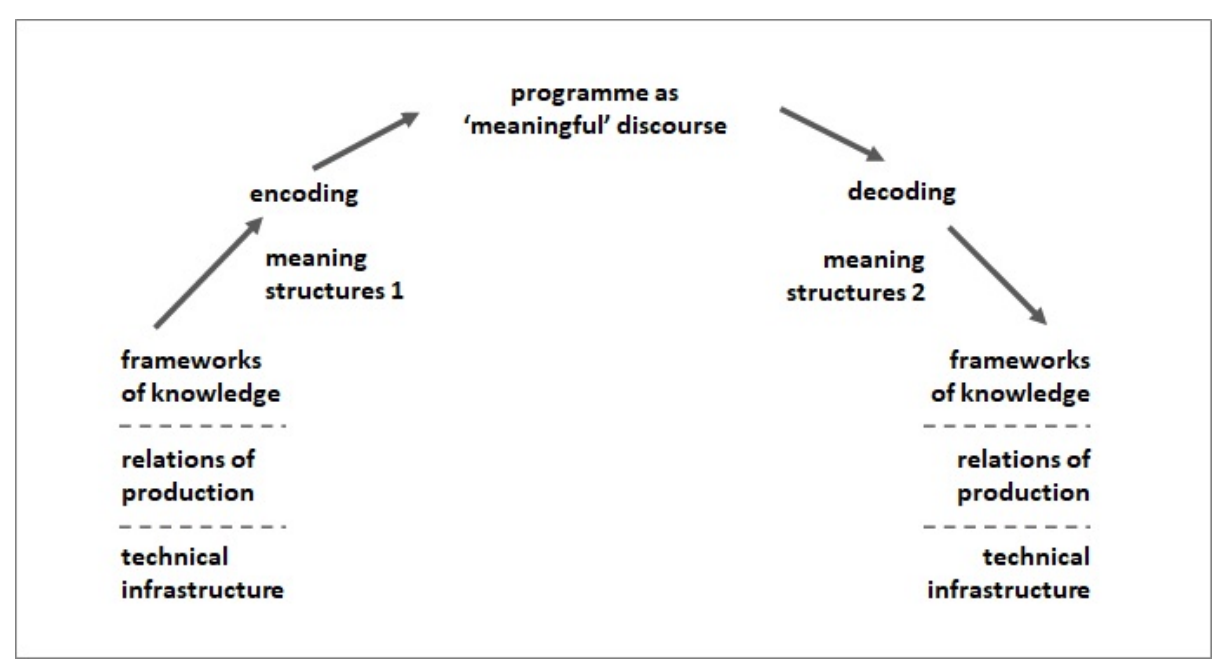

Figure 3. Stuart Hall's linear model of encoding and decoding in communication. 
With the passage of time, communication scholars started offering more complex variations of the Lasswell formula. Unidirectional acts of communication became complemented with the idea of feedback. More complex models arrived that described not just an act or a process but an entire system. One such example was DeFleur's model of mass communication (McQuail and Windahl [1982] 1993, p. 18; Figure 4).

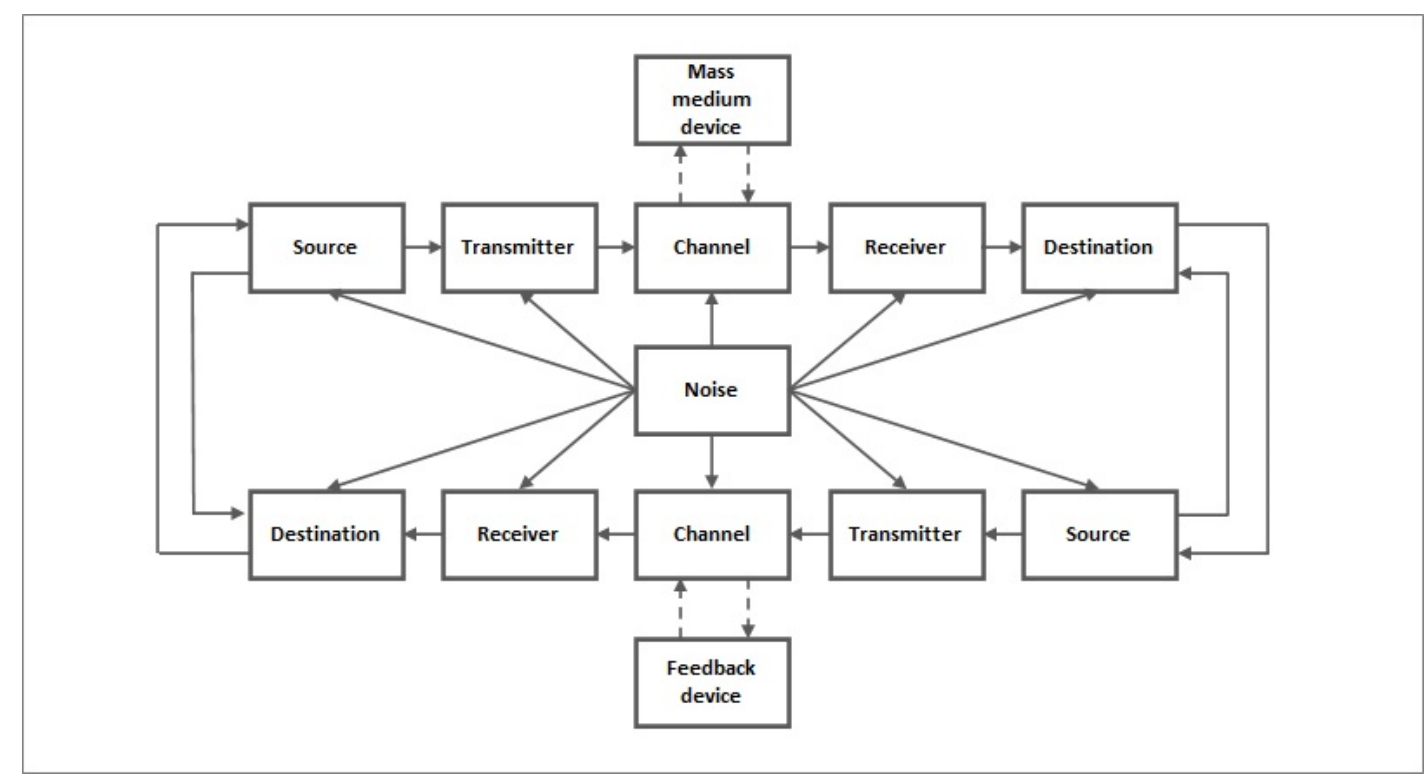

Figure 4. DeFleur's model of mass communication (according to McQuail and Windahl [1982] 1993, p. 18).

However, all the reiterations of the Lasswell model were intrinsically instrumental. As McQuail and Windahl wrote,

The Lasswell Formula shows a typical trait of early communication models: it more or less takes for granted that the communicator has some intention of influencing the receiver and, hence, that communication should be treated mainly as persuasive process. It is also assumed that messages always have effects. Models such as this have surely contributed to the tendency to exaggerate the effects of, especially, mass communication. On the other hand, this is not surprising when we know that Lasswell's interest at the time was political communication and propaganda. For analyzing political propaganda, the formula is well suited. (McQuail and Windahl [1982] 1993, pp. 14-15)

The information theory, developed at that time, only reinforced the Lasswellian "propagandist"-instrumental take on communications.

Marshall McLuhan was probably the first who outlined the divorce with the Lasswellian tradition in media studies. He highlighted the difference between the thenprevailing "transportation view" of communications and his own view, which he called a "transformation view". In his 1974 lecture at the University of South Florida, he stated that,

My kind of study in communication is really a study of transformation, whereas information theory and all the existing theories of communication that I know of are theories of transportation. All the official theories of communication studied in the schools of North America are theories of how you move data from point $A$ to point $B$ to point $C$ with minimal distortion ... [This] is a theory of transportation, and it has nothing to do with the effects which these forms have on us.... The problem in the transportation theory of communication is to get the noise, get the interference off the track and let it go through.

... I don't have much interest in that theory. My theory or concern is what these media do to the people who use them. What did writing do to the people who invented it and used it? What do the other media of our time do to the people 
who use them? Mine is a transformation theory, how people are changed by the instruments they employ ... (McLuhan 1974)

This rarely mentioned McLuhan's distinction between the "transportation" and "transformation" types of communication theories is essential for understanding media ecology, the field of enquiry regarding media and their impact on humans and the human environment.

\section{Distinguishing the Environmental from the Instrumental: A Media Ecological Take}

The instrumental approach is agency-centered, not media-centered. Media are seen as the instrument of someone's will, which is aimed at affecting someone else's will. The instrumental approach can be applied, with some reservations, in cybernetics, information theory, and communication studies. The ultimate goal of the instrumental approach to media effects is to figure out who is the user, what is their intent, and how the intended effect is achieved (if at all).

But for media studies, this approach is obviously a reductionist and even a distorting one. It diverts the attention of the explorer towards the user's bad or good intentions. Media are seen as more or less efficient means of content/intent transmission. Beyond their efficiency in transmission of the signal, the work of media themselves is omitted. As a result, it is the user's intents, not media features, that are declared to be responsible for the media effects. "Media research" based on user's characteristics belongs rather to anthropology and has little to do with media studies.

But the classification of the discipline is not the main issue. The main issue of the instrumental approach being transferred from information and communication studies to media studies is that the findings regarding media effects are almost always false because they relate to the user's agency, not to the media. They almost always "detect" conspiracy behind any media use, becoming a permanent illustration of the confirmation bias. Time after time, the instrumental approach to analyzing the effect of, for example, social media most likely reveals the same old well-known villains, which makes media analysis itself redundant. The "media" part in such research is used rather for rhetorical reinforcement than for the understanding of real mechanisms behind media effects.

Media as tools produce effects for people in a more or less controllable way. However, media as an environment have effects on people, and this occurs in uncontrollable ways and often even remains unrecognizable (Miroshnichenko 2020). The instrumental approach might help understand what people do with media, but it is blind in regard to what media do to people. This approach allows for the exploration of mediated human behavior, but it does not allow for the exploration of the media conditions that induced this behavior. As Marshall McLuhan once noted,

... and yet we still cannot free ourselves of the delusion that it is how a medium is used that counts rather than what it does to us and with us. This is the zombie stance of the technological idiot. (McLuhan 1969, p. 56)

If communication studies regard media as a means of communication and influence, media ecology explores media as an environmental force that modifies both the user and the environment regardless of what is communicated by whom to whom with what intent (hence "the medium is the message").

Another fundamental statement representing the basic idea of media ecology belongs to John Culkin, who said that "we shape our tools, and thereafter our tools shape us." The phrase is so McLuhanesque that is often mistakenly attributed to McLuhan himself. ${ }^{13}$ Culkin clarified: "Since our tools are extension of our senses, they shape the way we experience reality" (Culkin 1967, p. 52).

13 See an exploration on this matter in: McLuhan Galaxy blog. (1 April 2013). "We shape our tools and thereafter our tools shape us". https: //mcluhangalaxy.wordpress.com/2013/04/01/we-shape-our-tools-and-thereafter-our-tools-shape-us/ (accessed on 16 April 2021). 
Mediation predefines the ways humans interact with the environment. Hence, Neil Postman's definition:

Media ecology looks into the matter of how media of communication affect human perception, understanding, feeling, and value; and how our interaction with media facilitates or impedes our chances of survival.

The word ecology implies the study of environments: their structure, content, and impact on people. $<\ldots>$

Media ecology is the study of media as environments. (Postman 1970, p. 161)

Lance Strate, one of the founders of the Media Ecology Association, stated that media create a range of opportunities for their use, within which users start acting. He wrote that,

A medium is not like a billiard ball, producing its effects by striking another ball. Rather, it is more like the table on which the game is played. Put another way, a medium is not an actor, it is a stage on which human agents play their parts. As environments, media do not determine our actions, but they define the range of possible actions we can take, and facilitate certain actions while discouraging others. [ . . ] In other words, as Neil Postman (2000) has explained, cultures are formed within media, rather than media simply being produced by cultures.

(Strate 2008, p. 135)

Tools are designed for a user to make some changes to the environment or, more precisely, to the user's immediate surroundings. Any new medium is first introduced as a better tool to fulfill the old media's functions. However, then, a new medium unleashes its own power and "imposes" new media functions that lead to changes both in the user and the environment. Thus, at a certain point of use, a medium, if it has succeeded, starts changing the environment and the users themselves.

How does this turn from the instrument to the environment in media happen? This is, perhaps, the fundamental question of media ecology. The question may be presented in two parts:

(1) How do media reverse their effect from operating with the object to affecting the subject?

(2) How do media extend their effect from the user's immediate surroundings to the global natural and cultural environment?

The legacy, literature, and current discussion in media ecology allow the singling out of two possible pathways for a medium as an instrument to turn into a medium as an environmental force:

(1) A sensorial pathway from the instrumental to the environmental

(2) A cultural pathway from the instrumental to the environmental

The environmentalization of an instrument begins at the sensorial level. An instrument becomes successful when a user starts sensing an operated object and not the operating medium. For example, if a fisherman senses fish, not the rod, the rod as a tool has succeeded.

When a medium's use becomes unrecognizable for a sufficient number of users, its convenience starts reshaping their modus operandi. After that, a medium turns into an environmental force. The environmentalization of an instrument is completed when a user is not a person but a society.

\section{From Instrumental to Environmental: A Sensorial Pathway}

Any instrumental enhancement comes with an environmental "price" for the sensorium. To describe this duality of media's impact on the sensorium, Marshall McLuhan also used the dichotomy of service-disservice. As Pruska-Oldenhof and Logan put it, "Most analyses of media in the pre-McLuhan era focus on their service ignoring any disservices" (Pruska-Oldenhof and Logan 2017, p. 11). Indeed, the analysis of what media bring to humans and society most often emphasized the service of media in the form of 
their instrumental effect. The reverse effect of media on human practice, if noticed at all, was rather represented through moral philosophy than through what we would now call "media studies".

Meanwhile, the "moral assessment" of media's service and disservice has had an incredibly long tradition. This tradition was rooted in the discussion between the god Theuth and King Thamus in Plato's Phaedrus. As Mark Hansen put it in New Media (Hansen 2010, p. 173), the debate between Theuth and Thamus was "the primal scene of media innovation in Western thought."

Theuth and Thamus discussed what humans would gain from the invention of writing. The god Theuth, the inventor, insisted that humans would enhance their memory and increase their wisdom through writing, while Thamus, the king of Egypt (who also impersonates the superior god, Ammon), argued that humans would lose their memory, as they would become dependent on external inscriptions instead of developing inner notions and would obtain only a semblance of truth instead of truth; they would also obtain "the show of wisdom without the reality" (Plato 1892, p. 276).

Even though Theuth and Thamus cared more about the moral evaluation of the media effects of writing, their debate can also be read within the framework of media ecological analysis. The god-inventor and the king-inspector discussed the service and disservice of the new medium, writing, in terms of its impact on human faculties, such as memory and wisdom. Writing enhanced the effect of memory via externalization of data recording, as we would characterize it now, but obsolesced and, according to Thamus, degraded the internal memory. The function which the internal memory used to serve became better served, but the memory itself, the human faculty of memorizing, declined in use and subsequently worsened, thereby deteriorating the human "ability" of wisdom. Thus, Theuth advocated for the direct effect of writing, while Thamus warned against its "reversal" effect that would change the users themselves.

Marshall McLuhan described this reverse sensorial impact of a medium through the dichotomy of extension-amputation. The technological extensions of the body amplify abilities and intensify the burden of actions on the sensorium so much that they destroy the pre-existing balance of human perception. Because of this burden, the mental and sensory faculties that are extended outside the body become overloaded. This leads to the "numbness" of the organs or faculties, which were previously responsible for the execution of now media-extended functions, as McLuhan explained this mechanism in Understanding Media (McLuhan [1964] 1994, p. 42). To restore the cohesiveness of perception, the organism commits "a desperate and suicidal autoamputation, as if the central nervous system could no longer depend on the physical organs to be protective buffers against the slings and arrows of outrageous mechanism" (ibid., p. 43).

Thus, amputation (meaning the loss of organs/functions) is the flip side of the "extension of man" by media. McLuhan wrote:

Any invention or technology is an extension or self-amputation of our physical bodies, and such extension also demands new ratios or new equilibriums among the other organs and extensions of the body. (McLuhan [1964] 1994, p. 45)

The idea of atrophy, numbness, and even autoamputation of the organs and faculties because of the exteriorization of their functions by media illustrates the depth of the impact of instrumental use on the sensorium. Not only does the sensorium adjust to tools-they completely reshape it.

The reverse effect of media on humans can be observed in all acts of successful media use. For example, the use of fire for cooking changed the biochemical processes of the digestive system because a part of digestion was externalized into the thermal processing of food by fire. Interestingly, fire was once the main feature that distinguished humans from animals, a fact that is well reflected in the myth of Prometheus or in Kipling's story of Mowgli. However, in the course of technological progress, all the functions of fireheating, cooking, lighting, protection-are now performed by other technologies, often not involving fire at all. Even smoking no longer requires a starting flame since e-cigarettes have 
become popular. The extension of the human ability to control fire by other technologies "amputated" this skill from the human skillset. We no longer use the Promethean gift.

Media ecology endeavors to look at the relations between the immediate instrumental effect of a medium and the indirect environmental consequences of its use. Even though Marshall McLuhan himself refused to recognize his ideas as a wholistic theory, many of his concepts constituted the apparatus of such instrumental/environmental media analysis. For example, the concept of extension/amputation can be used for the analysis of the environmental effect of writing and subsequent technologies of information storing and transmission, which started from the debate between Theuth and Thamus.

Theuth advocated for extension and its gain, while Thamus warned about amputation and its harm. Writing enhanced recording but-and precisely because of this enhancementamputated a part of the function of memory by recording "data" outside of the brain. The decline of the inner function of memory has become even more visible since the advance of the internet and digital gadgets. Cellphones, for example, memorize our friends' phone numbers and, as a result, we do not need to remember them. This has led to the "autoamputation" of this function in our brain. Eventually, the function of memorizing phone numbers is executed much more reliably by the extension of this operation in a medium. However, our bodily/mental ability, which was responsible for this, "weakens" because of it. This is the price of media enhancement. The smartphone as a medium extends and amputates abilities and respectively changes the ratio of senses and skills not just for a user but for humankind in general.

The "show of wisdom", as Thamus labeled it, which began with writing, now continues to grow on the back of digital media. Google and Wikipedia quickly became an "outsourced" but instantly available function of everyone's personal memory. The resultant effect of memory use has incredibly improved but at the expense of the "atrophy" of the "organic" memory that was responsible for the task in the past.

With less use, the "organic" memory is less trained and is losing its ability to memorize large or complex data. This function is no longer needed to be fulfilled internally by the biological processing capacity. The "outsourced" memory has been empowered, but "organic" memory is becoming impaired. With this, the attention span is shrinking because, for operation with outsourced memory, the skill of outward browsing, not inward diligence, is required. In its turn, the shrinkage of the attention span leads to the weakening of the individual ability to focus for long on a single task for a deeper insight.

The average individual intelligence, as King Thamus warned, decreases in these circumstances. However, the collective intelligence, as Theuth might imply, increases tremendously. Additionally, the type of individual intelligence is changing, as it is becoming more emotional and adept at multitasking and less rational and diligent.

Social media has replaced part of the mental and psychological abilities that were responsible for socializing. Algorithms have enhanced socialization through automatization. They gather all of a person's friends in one place, suggest potential friends, prioritize certain friends' posts in the newsfeed, remind of friends' birthdays, and so on. The very "skill of socializing" has been extended by the new medium. Simultaneously, the individual's necessity to befriend someone offline vanishes and, therefore, the individual "skills of befriending", especially in the younger generations, are becoming numb, if not already amputated.

The impact of this media effect on human abilities and, in a broader sense, on the sensorium is incredible, considering the number of connections made available through social media. Socialization has overcome physical limits. Never before has humankind had such a massive "amount of friendship". However, this global enhancement of human socialization comes with a price. One of the most harmful consequences of digitally accelerated socialization is polarization (Mir 2020, p. 322). Precisely because social media are an extremely successful instrument of socialization, they impact the sensorium and, therefore, become an environmental force that changes people and society. 
Thus, when a medium is successful, its sensorial media effect leads to a cultural media effect.

\section{From Instrumental to Environmental: A Cultural Pathway}

The cultural pathway of a medium from instrumental use to environmental force relates, formally, to the scale of use. After its sufficient proliferation, a medium gains cultural momentum and unleashes its environmental potential.

When used by a person, a fence is an instrument to protect and defend, a further extension of the skin, beyond clothes and huts. However, when used by a culture, a fence is an environmental force that transforms a nomadic tribe into a sedentary culture. Similarly, what seemed to be just the instrumental use of a medium in an isolated act (or a series of acts) becomes an environmental force when the user is not an individual but an entire culture.

As McLuhan noted in The Medium Is the Massage,

All media work us over completely. They are so pervasive in their personal, political, economic, aesthetic, psychological, moral, ethical, and social consequences that they leave no part of us untouched, unaffected, unaltered. The medium is the message. Any understanding of social and cultural change is impossible without a knowledge of the way media work as environments. (McLuhan and Fiore 1967, p. 26)

The cultural impact of media was explored by Harold Innis, a predecessor of media ecology. Innis managed to identify the link between the sensorial characteristics of a dominant communication medium of a certain epoch and the civilizational characteristics of this epoch. Thus, in Empire and Communications (Innis 1950), Innis argued that stones with hieroglyphs or clay tablets, being durable and heavy and, therefore, time-biased media, underlay the rigid and hierarchical Egyptian and Sumer civilizations. Light and easily transported papyrus, a space-biased medium that was "suited to wide areas in administration and trade" (Innis 1950, p. 7), allowed the civilization using it to expand through territories, as in the case of Rome. He stated that,

Materials which emphasize time favour decentralization and hierarchical types of institutions, while those which emphasize space favour centralization and systems of government less hierarchical in character. (Innis 1950, p. 7)

The cultural pathway of a medium from instrumental use to environmental impact can be best explored using the example of the phonograph, one of the beloved media devices among media ecologists. Marshall McLuhan devoted an entire chapter of Understanding Media (McLuhan [1964] 1994) to the phonograph. He started his exploration from the sensorial characteristics of this medium as an instrument: in the chapter's subtitle, he called it "The toy that shrank the national chest" (McLuhan [1964] 1994, p. 275). He called the phonograph "an extension and amplification of the voice that may well have diminished individual vocal activity, much as the car had reduced pedestrian activity" (ibid., p. 275).

Interestingly, McLuhan pointed out that " ... the phonograph was involved in many misconceptions, as one of its early names-gramophone-implies." In fact, Edison expected that his invention would become a "telephone repeater" - a tool for recording telephone conversations for storing and future reference, similar to what writing does to oral speech. So, the phonograph as an instrument was intended to record speech as it sounds, phonetically. However, this instrumental expectation was transcended by the environmental outcome of this medium's use. The phonograph became "a means of access to all the music and speech of the world", as McLuhan noted (ibid., p. 277).

The example of the phonograph shows that a new medium, if successful, always unfolds its own environmental force, which will most likely be unforeseen by a user or even the inventor, because the user and the inventor "march backwards into the future", to use McLuhan's metaphor ("We look at the present through a rearview mirror. We march 
backwards into the future"-McLuhan and Fiore 1967, p. 77). The phonograph was initially meant to better perform or enhance a function of an old media-writing, telegraph, and telephone, related to the recording and transmission of speech. A new medium is always expected to enhance a function of an old one, but then, if successful, it unleashes its own environmental potential and reshapes both the user and the environment.

What was the environmental potential of the phonograph that was unrecognized by its inventor and early users? This is the central question of environmental media analysis: What environmental force gets unleashed by this medium as an instrument when its collective use grows large enough?

We can extend McLuhan's analysis of the phonograph by answering these questions. The case of the phonograph clearly shows how the instrumental becomes environmental. The phonograph detached audial entertainment from the time and space of performance. Edison created the instrument that emancipated audial entertainment from the constraints of time and space. Listening to musical and vocal performances became transportable, storable, and saleable.

At this point, a new medium undergoes a test of social scalability. How many users will willingly join the use of it? The process is viral: the new environmental force absorbs more users, and they cause it to proliferate further. The environmental force unleashed by a new medium reshapes the environment through the growth of the medium's clientele.

The environmental force that came with the phonograph transcended its instrumental use and the phonograph itself. The real media effect belongs not to the instrument but to the environmental force it unleashes. The media function of the device was listening to performance wherever and whenever you want, regardless of the time and space in which the performance was produced. The detachment of entertainment from the time and space of performance entailed the appearance of the entire sequence of similar media, such as radio, the record player, or the tape recorder. As McLuhan noticed, "it was radio that finally injected a full electric charge into the world of the phonograph" (McLuhan [1964] 1994).

A new, virtual, and accessible venue for musical performance was created. The growth in a new medium's users creates the demand for content production specific to this medium. These new wineskins, at first made for old wine-recording phone conversations or just oral speech, then required a new wine-the production of performance recordings. The collective use of recordings instead of listening to live performances did not replace performances but increased their number in order to produce even more records and also extended their outreach, involving ever-more artists, producers, and consumers.

This created the craft and industry of music recording. Distribution increased, competition was boosted, selection broadened, and the industrial market for singers and musicians appeared. A musical revolution started that brought about jazz, the foxtrot, crooners (a by-product of the invention of the microphone, a derivative of the phonograph's "instrumental" development), and all the genres and styles of what later became pop music.

Commercial distribution extended social proliferation. The electrical venue for performances turned out to be much more democratic than the physical one. The mass-market appeared: not only middle-class and upper-class but the masses, too, joined into listening to performances. This, too, affected the specificity of content production. A child of recorded music and the mass-market-show business was born.

Long story short: Edison begat the phonograph, the phonograph begat listening freed from the time and space of performance, emancipated listening begat the recording industry, the recording industry begat popular music, popular music begat show business, show business begat fandom culture, fandom culture begat the cult of celebrity, and the cult of celebrity begat Trump. (As the New York Times wrote, "'Apprentice' celebrity fueled a myth that propelled him to the White House ... His genius, it turned out, wasn't running 
a company. It was making himself famous-Trump-scale famous-and monetising that fame"14).

Here we see an exemplar of the media "butterfly effect" - Edison wanted to merely record phone conversations, and this somehow ended in Trump's presidency.

One could perceive Trump's presidency as an accidental fluctuation in the force fields of media evolution. This, however, was not an accident. Trump, or a Trump-like politician, was as much an inevitable outcome of the phonograph's development (or whatever could have come instead of the phonograph in this media-ecological niche-the recording and broadcasting of music and vocal performances), as Hitler was a logical outcome of radio (the idea first expressed by McLuhan in Understanding Media).

As strange as it may sound, the logic behind the sequence of environmental events that led from the invention of the phonograph to the election of Trump was well-known to both founders of media ecology. Marshall McLuhan wrote in Understanding Media:

In [Edison's] own case, his determination to give the phonograph, like the telephone, a direct practical use in business procedures led to his neglect of the instrument as a means of entertainment. Failure to foresee the phonograph as a means of entertainment was really a failure to grasp the meaning of the electric revolution in general. In our time we are reconciled to the phonograph as a toy and a solace; but press, radio, and TV have also acquired the same dimension of entertainment. Meantime, entertainment pushed to an extreme becomes the main form of business and politics. (McLuhan [1964] 1994, p. 277)

Neil Postman devoted his main work Amusing Ourselves to Death: Public Discourse in the Age of Show Business (Postman [1985] 2005) to the effect that television has had on culture and politics. Television can be seen as one of the phonograph's successors as "a means of access to all the music and speech of the world" (McLuhan). Postman stated that politicians, including presidents, became entertainers because of television. They focus more on how they impress than on what they do. He wrote:

Our priests and presidents, our surgeons and lawyers, our educators and newscasters need worry less about satisfying the demands of their discipline than the demands of good showmanship. Had Irving Berlin changed one word in the title of his celebrated song, he would have been as prophetic, albeit more terse, as Aldous Huxley. He need only have written, "There's No Business But Show Business." (Postman [1985] 2005, KL 1721)

The case of the phonograph shows that the use of the instrument of speech recording does more than just recording speech. By detaching sounds from the time and space of their performance, the phonograph creates self-sustaining conditions for new cultural practices, which reshape society in a certain way. This is why the study of media use is the question of ecology and not just of communication studies.

\section{The Question of Responsibility for Media Effects}

Within the instrumental approach to media effects, the role of the phonograph in shaping a pop culture that thereafter impacted public life and politics may raise a question regarding the role of Edison.

Is Edison responsible for Trump?

This question might even create a somewhat paradoxical paradigm for assessing the ultimate human price society pays for the most significant media inventions. For example, as a sort of intellectual provocation, it can be stated that Marconi is likely "responsible" for killing more people than Gutenberg or Berners-Lee. Even though the Gutenberg invention obviously caused religious wars, social revolutions, and one of the biggest waves of resettlement and colonization, radio as a communication tool and a means of mass

14 McIntire, Mike, Buettner, Russ, and Craig, Susanne. (28 September 2020). "The President's taxes". The New York Times. https:/ / www.nytimes.com/ interactive/2020/09/28/us/donald-trump-taxes-apprentice.html (accessed on 16 April 2021). 
communication completed the job of the telegraph in creating imperialism and contributed, both instrumentally and environmentally, to the two biggest wars in human history.

As Postman testified, "Innis worried that a medium that emphasizes space over time is likely to make a culture obsessed with military conquest" (Postman 2000). Of all communication media, electronic media are the most space-biased ones. Additionally, of all electronic media, the ultimately space-biased is radio. The telegraph and television require physical recording (the telegraph type to finalize message delivery, filming in TV production) or staged scenery (TV studio) which gives them at least some time dimension to last a bit longer than a moment of sending/receiving.Radio, in the meantime, can technically function with no fixation in time but with any-length stretching in space. This quality makes radio a perfect communication medium for travels and military coordination and a perfect mass medium for simultaneous mass agitation-a "tribal drum", as McLuhan called radio. These are prerequisites for a global multinational war.

On the other hand, emancipated reading, the main environmental effect of Gutenberg printing press, had a relatively "low" death toll, perhaps due to the intellectual specificity of reading. As for the web, the invention of Berners-Lee, its main environmental effect was the emancipation of authorship (Miroshnichenko 2014). Even though this emancipated authorship triggered protests against political establishments around the globe, sometimes quite bloody ones, and certainly facilitated the biggest-ever wave of migration in human history, the nature of this media effect does not allow for the unfolding of a full-scale industrially backed war. By representing and also faking a vast diversity of actors (as opposed to the unifying effect of radio), the internet and social media created rather the conditions for "hybrid wars", the most humane types of war, including civil-armed conflicts related to polarization (Mir 2020).

We have never thought about the responsibility of Gutenberg, Marconi, or Berners-Lee (perhaps, "the collective Berners-Lee" would be a more accurate signifier) in terms of the ultimate price that humankind pays for their inventions, but we could. Media ecology may offer an apparatus for such an exercise.

Interestingly, the question of the responsibility of the media inventor/producer, as odd as it may seem, is not that new or unusual. King Thamus condemned the invention of the god Theuth, writing, pointing to the "environmental" harm this invention would bring to human wisdom. The inventor, who insisted on the benefit of his invention, was warned about its forthcoming harm.

By the way, according to Plato, Thamus denied Theuth's ability to justly evaluate the "utility or inutility" of writing because Theuth himself was "the father of letters", meaning their inventor. This means that a proponent of instrumental media use might or even has to be blind towards the environmental consequences. The utmost cynical reading of the fable's moral is that the inventor or the proponent of a new medium morally or financially profits from its instrumental use and proliferation, while society in general both benefits from its use and pays for its environmental harm.

By harm, society often understands any changes in the status quo (or in the old ratio of "organs and extensions") because these changes are painful by themselves, which is implied even by the language chosen by McLuhan for their description: "numbness", "autoamputation" ... Thus, even before a new medium breaks something in society or creates some negative social impact, the very change caused by a new medium is already considered harmful, as it disrupts personal and social habits and establishments. This is yet another reading of "the medium is the message": the effect of a new medium's successful introduction is inevitably disruptive, regardless of the content carried by this medium. The true message of any new medium is an opportunity but also a disruption. The medium is the breakage.

How are the gains from opportunities and the price for the harm of media use distributed in society? Obviously, the media inventor or the media producer most often receives all the credits. However, when it comes to harm or losses related to media, it is the society in general that deals with both the gains and harms because, when harm is done 
by an environmental force, it is hard to assign any agency to it. An environmental media force is seen as emerging independently rather than caused by someone individually. Only cinematographic villains are individually able to cause harm of an environmental scale.

Postman emphasized the environmental potential of a medium. " ... We may learn from Thamus the following: once a technology is admitted, it plays out its hand; it does what it is designed to do", he stated (Postman 1992, KL130-132). Thus, elaborating on Postman's thought, it can be admitted that Theuth could not have controlled the consequences of the future use of writing. In the court with Postman as a judge, Marconi is not guilty, even though radio (with the telegraph) facilitated the two biggest wars in human history.

This kind of "instrumental vs. environmental" analysis can be applied to any medium to put it into the framework of the juridical-like assessment of guilt and responsibility. For example, cars in instrumental use and cars as an environmental force can cause different consequences in terms of defining responsibility for their media effect.

(1) The instrumental effect of the car is simple: as an extension of human legs, it is a means of transportation. In the case of harm done, it is also quite simple to define guilt and responsibility: it is either the producer or the user of the car.

(2) The environmental view of the media effect caused by the car is much more sophisticated. The car formed the entire new economy. Cars entailed the creation of the highway grid, which caused the development of the highway service infrastructure and the decline of the previous infrastructure with all its accompanying subcultures, such as traditional inns. Cars increased the economic and geopolitical significance of oil and contributed to the economic prosperity of some Middle East states. Cars changed urban settings, created new suburbs and suburban malls, and, therefore, new retail logistics and merchandising. Cars created a completely new experience of sexual relations for an entire generation in the 1950s and later, and so on and so forth.

Now: who is responsible for all of this? It is possible to discuss historical and cultural responsibility, but who is to blame for, say, the death of traditional inns or the sexual libertinism facilitated by the car? Cars changed human conditions, and if we see this change as harmful, where should we draw the line of legal responsibility?

The duality of the instrumental and environmental views of media creates an even more complex legal dilemma when applied to the internet. A user can be seen as responsible when he or she calls for violence and uses social media as an amplifier. However, who is responsible for an environment that favors polarization and in which any message, good or bad, can be amplified?

It is even more complicated when it comes to a producer.

The responsibility of Mark Zuckerberg, the tool's producer, might be seen differently within the instrumental and environmental approaches. This paper does not offer a definitive solution for each approach, but the distinction between these approaches might be important to understand for practical juridical and legislative reasons. For example, which take on media, instrumental or environmental, should be adopted during hearings in the US Congress or any other legislature or court regarding the role of social media and their management in political development?

The situation becomes even more complicated when the media producer is the media owner. While their "environmental responsibility" remains debatable, a new instrumental dimension appears-the dimension of using media as an instrument for profit extraction.

A new category of agency may appear: the "owner" of a media environment, the one who profits from it, who can control it, and, therefore, can adjust environmental settings, including restricting or allowing someone's access. The exploration of this perspective may become particularly important as more and more human activities relocate onto the digital environments. The digital environments may be seen as human-made premises, which have their producers, engineers, owners, and maintenance staff, whose liabilities can be relatively easily spelled out.

Interestingly, the environmental responsibility of the media premises' owner for the use of a medium as a profit-extracting instrument has significantly increased since the 
leading social media platforms de-facto left the position of platform neutrality ("we are not responsible for what users express") and started effectively controlling content and users. A paradox appeared: under the threat of stricter regulation, Facebook and other social media banned Trump and his extremist supporters, in so doing admitting responsibility for the content and user selection and thereby exposing themselves ... to stricter regulation. If they can adjust the environmental settings in their digital premises, then they admit themselves as being responsible for "proper" adjustment. Confession is the queen of evidence.

However, the extrapolation of "real estate property management" norms onto the digital environment needs to be checked for their applicability. People might have control over media as instruments, but how much control do they have over the environmental forces unleashed by media? The truly environmental view of media is deterministic: upon being exposed to a certain technological development, people, in fact, have not much choice but must follow the "iron logic" of media's multiplication and replenishment. Humans can be seen not as producers and users of media but rather as biological carriers of media and media evolution. As McLuhan saw it,

Man becomes, as it were, the sex organs of the machine world, as the bee of the plant world, enabling it to fecundate and to evolve ever new forms. The machine world reciprocates man's love by expediting his wishes and desires, namely, in providing him with wealth. (McLuhan [1964] 1994, p. 46.)

According to this view, people might use media for their benefit and pay a price for it, but these relations are not consumerist; they are rather symbiotic. Media need people to evolve. For this reproductive service, media provide humans with some utilities. Further speculations may even reverse the relations: humans become media for media, while the latter is the true subject and beneficiary of media evolution.

These sorts of speculations may also imply the inevitability and invariability of media development. Can Facebook exist as an environment of instant socialization for millions without the mechanisms of engagement stimulation? Or, as Postman concluded regarding the case of Theuth and writing in a quote above, "... once a technology is admitted, it plays out its hand; it does what it is designed to do".

Accelerated socialization is the greatest and most human-oriented service provided by media throughout all of history because it allows for self-actualization through others, which is the highest value in Maslow's hierarchy of needs. The mechanisms of virality and relevance that made Facebook such an amazing tool are simultaneously those exact mechanisms that provide better ad business and, therefore, better profit extraction.

However, the accelerated engagement inevitably leads to more noise and more efforts needed to overcome this noise. Eventually, the amplification of extremes and polarization become inevitable side effects of this dependency between better self-actualization and better ad-targeting on Facebook and other social media in general (Mir 2020, p. 335).

Thus, the same environmental force-artificially accelerated personal engagement-is behind both the service and disservice of this medium. The service of self-actualization through others on social media is maintained by profit-extraction, which, in a sense, is an institutional maintenance fee for this service's very existence. Restricting mechanisms of engagement degrades not only the business model and the owner's profit but, possibly, the service's capacity of the medium to maintain itself.

Technically, it is quite possible to impose restrictions on users' self-actualization on a certain platform. The recent ban of Trump and his extremist supporters by Facebook and Twitter proves that a concrete media platform can be politically responsive. However, the same is not true for the environmental force. The environmental force that emerges on the back of social media is the acceleration of dual-purpose user engagement aimed simultaneously at users' socialization and the platform's profit, with polarization as an inevitable side effect. The regulatory restrictions, even if technically possible, weaken the maintaining mechanism of the platform and create the conditions for alternatives. The environmental force sprouts up through other media devices of this niche, such as Parler, TikTok, Telegram, Clubhouse, or some other, yet-to-be-created platform. 
The name of the media device does not matter. What matters is that the social media platforms maintain and develop themselves via extracting value from users' engagement; otherwise, they would deteriorate and yield the space to others. However, the environmental niche itself would inevitably be filled with platforms that perform this function through this mechanism.

Furthermore, the restrictions of self-expression on social media risk turning into the endless cat-and-mouse regulation game of censorship, which might lead to consequences much worse for democracy than the harm it is supposed to regulate.

\section{Conclusions}

The regulation of new media presents unprecedented challenges. When an instrument was a physical tool with an obvious and direct instrumental use, it was easy to single out the responsibility for harm done with the use of this medium. In the digital environment, the instrumentality of media swallows the user. We act and live inside the instrument. To grasp the oddity of this condition, one can imagine a caveman resettling into a stone ax.

A medium has become not just an environmental force but an environment in a literal sense. That is why legal judgment regarding media now is impossible without media expertise aimed at distinguishing between the instrumental and environmental effects of media use.

Considerations of this kind lead to a conclusion that can frame two approaches to the responsibility for media use.

(1) When the instrumental approach is not distinguished from the environmental one, media tend to be judged as a simple amplifier of an agency behind the media use, with a tendency for this agency to be seen as evil. This approach unavoidably ends up being prosecutorial-biased.

(2) When the instrumental and environmental approaches are distinguished, the necessity emerges to limit the responsibility for a media effect to an instrumental use and, therefore, to the user or producer. At the same time, the most impactful cultural force of media relates to their environmental effect, which producers or users of media cannot be responsible for. The environmental effects of media should be dealt with outside of the concepts of guilt or personal responsibility because an environmental force has no user, producer, or agency.

At the same time, as humans resettle into the media environment, the question of "environmental" responsibility may arise. For now, the legal system may not be ready to answer this question. Media ecology, on the other hand, can provide some solid basis for exploring the connection between the instrumental use and environmental effect of media for future legal enquiries into the responsibility for the media environment.

The complexity of the instrumental-environmental effects of new media also suggests the possibility that the customary (for the physical world) level of regulation reliability may never be achieved in the digital environment. Specifically, in social media, some restricting rules can be established, but the disservice of a medium cannot be removed without disrupting its service.

The environmental view of media effects may imply that the human will might have limited agency or no agency at all in the environmental regulation. These are media environmental forces, not humans, that impose their rules on the effects of media use. King Xerxes might have thought he was punishing the sea with lashes for not providing the needed conditions, but neither did the sea "respond" to the punishment nor did the needed conditions appear. The only effect was the show trial of the environment by the mighty king. This was likely an important political demonstration at the time, but it eventually ended up being mocked by posterity-and thus was the effect of Xerxes' "regulation".

In the logic of media ecology, the interference of human agency in environmental forces hardly reverses or cancels the effects of those forces but rather creates new environmental forces with new effects. Therefore, a new or a newly disturbed balance of forces appear, in which benevolence to users is neither guaranteed nor predictable. By default, it can be 
stated that regulation of the media environment does not "fix" the media environment but creates a new and different one, in which the "fixed" service is accompanied by a new disservice.

The simplest example: the introduction of editorial selection in social media platforms does not suppress the dissent in society but rather gives proof of suppression and evokes the reinforced release of this dissent through other channels/platforms. The environmental force that accelerates user engagement for the users' socialization and the platforms' profit will always tend to abandon the platforms with higher regulatory pressure and move toward the platforms with lower regulatory pressure. If this happens, a regulatory zeal will produce grey zones or even "black markets" of self-actualization, just because this environmental force, already unleashed, will searche for an alternative release.

This means that such interference will create new environmental forces and will lead to effects that are the opposite of what was intended. The most probable outcome will be that the spontaneous amateur dissent will turn into a well-established political stance or even organized conspiracy. What might be seen as a solution for a platform will become a new trigger for the media environment as a whole.

It well may be that environmental regulation is serious business not because of its effect on the environment but because it provides moral, political, and financial profit for the parties involved. So, it will proceed regardless of whether the regulation itself is truly efficient or not. The ability to capitalize on environmental regulation might end up being the only parameter of efficiency of environmental regulation. Moreover, considering the partiality of "parties involved", such regulation will only worsen what it is supposed to better.

To make an even more radical statement, any regulation of the media environment aimed at modifying the behavior of "others", if efficient at all, inevitably leads to new disturbances in the environmental forces, and the effect will always be the opposite of what is intended. The only benevolent effect may be produced by regulation aimed at the "self", which narrows the prospects of efficient and benevolent regulation of the media environment to media education and media hygiene.

Such a conclusion is most likely difficult to accept within jurisprudence and legislation, but it is a legitimate take within media ecology, and it can be a discussion framing point for further consideration. Therefore, experts and officials in legislature and jurisprudence should be prepared for the impossibility of total or even satisfactory regulation in the digital environment. The question might be not about the elimination of the negative media effects but about learning how to live with them.

Funding: This research received no external funding.

Institutional Review Board Statement: Not applicable.

Informed Consent Statement: Not applicable.

Data Availability Statement: Not applicable.

Conflicts of Interest: The authors declare no conflict of interest.

\section{References}

Benkler, Yochai, Robert Faris, and Hal Roberts. 2018. Network Propaganda: Manipulation, Disiformation, and Radicalization in American Politics. New York: Oxford University Press.

Culkin, John. 1967. Each culture develops its own sense ratio to meet the demands of its environment. In McLuhan: Hot and Cool. Edited by Gerald Stearn. New York: New American Library, pp. 49-57.

Enli, Gunn. 2017. Twitter as arena for the authentic outsider: Exploring the social media campaigns of Trump and Clinton in the 2016 US presidential election. European Journal of Communication 32: 50-61. [CrossRef]

Hall, Stuart. 2012. Encoding/Decoding. In Media and Cultural Studies: KeyWorks, 2nd ed. Edited by Meenakshi Gigi Durham and Douglas M. Kellner. Oxford: Wiley-Blackwell, pp. 137-44. First published 1973.

Hansen, Mark B. N. 2010. New Media. In Critical Terms for Media Studies. Edited by William. J. T. Mitchell and Mark B. N. Hansen. Chicago and London: University of Chicago Press, pp. 172-85.

Innis, Harold. 1950. Empire and Communications. Oxford: Clarendon Press. 
Lasswell, Harold. 1948. The Structure and Function of Communication in Society. In The Communication of Ideas. Edited by Lyman Bryson. New York: Institute for Religious and Social Studies, pp. 37-51.

McLuhan, Marshall. 1994. Understanding Media. The Extensions of Man. Cambridge, Massachusetts: The MIT Press. First published 1964.

McLuhan, Marshall. 1969. Playboy Magazine Interview. Playboy Magazine, March.

McLuhan, Marshall. 1974. Marshall McLuhan Speaks Special Collection: Living in an Acoustic World. University of South Florida Public Lecture. Available online: http:/ / www.marshallmcluhanspeaks.com/lecture/1970-living-in-an-acoustic-world/ (accessed on 16 April 2021).

McLuhan, Marshall, and Quentin Fiore. 1967. The Medium Is the Massage: An Inventory of Effects. New York, London and Toronto: Bantam Books.

McQuail, Denis, and Swen Windahl. 1993. Communication Models for the Study of Mass Communication. London: Routledge. First published 1982.

Mir, Andrey. 2020. Postjournalism and the Death of Newspapers. The Media after Trump: Manufacturing Anger and Polarization. Available online: https:/ / www.amazon.com/dp/B08GWWXDG7 (accessed on 16 April 2021).

Miroshnichenko, Andrey. 2014. Human as Media. The Emancipation of Authorship. Available online: https://www.amazon.com/dp/B0 OHLT7H0E (accessed on 16 April 2021).

Miroshnichenko, Andrey. 2020. The hardware and software of Trumpism: A figure/ground analysis. Explorations in Media Ecology 19: 55-84. [CrossRef]

Owen, Diana. 2019. The Past Decade and Future of Political Media: The Ascendance of Social Media. Towards a New Enlightenment? A Transcendent Decade. BBVA, OpenMind project. pp. 347-65. Available online: https://www.bbvaopenmind.com/en/articles/thepast-decade-and-future-of-political-media-the-ascendance-of-social-media/ (accessed on 16 April 2021).

Plato. 1892. Phaedrus. Translated by Benjamin Jowett. London: Oxford University Press, The Project Gutenberg. Etext of Protagoras. [Etext \#1591]. Available online: https:/ / oll.libertyfund.org/title/jowett-the-dialogues-of-plato-vol-1\#lf0131-01_head_030 (accessed on 16 April 2021).

Postman, Neil. 2005. Amusing Ourselves to Death: Public Discourse in the Age of Show Business. Kindle ed. New York: Penguin Publishing Group. First published 1985.

Postman, Neil. 1970. The reformed English curriculum. In High School 1980: The Shape of the Future in American Secondary Education. Edited by Alvin C. Eurich. New York: Pitman, pp. 160-68.

Postman, Neil. 1992. Technopoly: The Surrender of Culture to Technology. Kindle ed. New York: Knopf Doubleday Publishing Group.

Postman, Neil. 2000. The Humanism of Media Ecology. Keynote Address Delivered at the Inaugural Media Ecology Association Convention at Fordham University, New York, New York. June 16-17, 2000. Proceedings of the Media Ecology Association, Volume 1, 2000. Available online: https://www.media-ecology.org/resources/Documents/Proceedings/v1/v1-02-Postman.pdf (accessed on 16 April 2021).

Pruska-Oldenhof, Izabella, and Robert K. Logan. 2017. The Spiral Structure of Marshall McLuhan's Thinking. Philosophies 2: 9. [CrossRef]

Sapienza, Zachary S., Narayanan Iyer, and Aaron S. Veenstra. 2015. Reading Lasswell's Model of Communication Backward: Three Scholarly Misconceptions. Mass Communication and Society 18: 599-622. [CrossRef]

Strate, Lance. 2008. Studying Media AS Media: McLuhan and the Media Ecology Approach. MediaTropes, eJournal I: 127-42. 